\title{
EVALUATION OF CONVERTING LANDSAT DN TO TA AND SR VALUES ON SELECT SPECTRAL INDICES
}

\author{
A. L. Gettinger ${ }^{1}$, R. Sivanpillai ${ }^{2}$ \\ ${ }^{1}$ Dept. of Ecosystem Science and Management, University of Wyoming, Laramie, WY 82071, USA, ORCID: 0000-0003-0664-2621 \\ - agettin1@uwyo.edu \\ ${ }^{2}$ Wyoming GIS Center, University of Wyoming, Laramie, WY 82071, USA, ORCID: 0000-0003-3547-9464 - sivan@uwyo.edu
}

KEY WORDS: Pre-processing, Digital number, ToA, Surface reflectance, Spectral indices, Landsat

\begin{abstract}
:
The complete archive of images collected across all Landsat missions has been reprocessed and categorized by the U.S. Geological Survey (USGS) into a three-tiered architecture: Real-time, Tier-1, and Tier-2. This tiered architecture ensures data compatibility and is convenient for acquiring high quality scenes for pixel-by-pixel change analyses. However, it is important to evaluate the effects of converting older Landsat images from digital numbers (DN) to top-of-the-atmosphere (TA) and surface reflectance (SR) values that are equivalent to more recent Landsat data. This study evaluated the effects of this conversion on spectral indices derived from Tier1 (the highest quality) Landsat 5 and 8 scenes collected in $30 \mathrm{~m}$ spatial resolution. Spectral brightness and reflectance of mixed conifers, Northern Mixed Grass Prairie, deep water, shallow water, and edge water were extracted as DNs, TA, and SR values, respectively. Spectral indices were estimated and compared to determine if the analysis of these land cover classes or their conditions would differ depending on which preprocessed image type was used (DN, TA, or SR). Results from this study will be informative for others making use of indices with images from multiple Landsat satellites as well as for engineers planning to reprocess images for future Landsat collections. This time-series study showed that there was a significant difference between index values derived from three levels of pre-processing. Average index values of vegetation cover classes were consistently significantly different between levels of pre-processing whereas average water index values showed inconsistent significant differences between pre-processing levels.
\end{abstract}

\section{INTRODUCTION}

\subsection{Landsat Overview and Remote Sensing Importance}

Landsat satellites have been collecting images since 1972 and are administered by the United States Geological Survey (USGS) in conjunction with the National Aeronautics and Space Administration (NASA) (Straub et al., 2019). These satellite images are provided at no-cost (USGS, 2018) and are utilized for a wide variety of applications including improving water use in vineyards (Ecker, 2020), wildfire and clear-cut mapping (Schroeder et al., 2011), invasive species mapping (Evangelista et al., 2009), and evaluating flooded areas (Sivanpillai et al., 2020, Wang et al., 2002).

\subsection{Pre-processing}

Prior to an image being used, pre-processing is often performed (Jiang et al., 2018) to try to reduce the effects from the atmosphere, the sun, topography, and the sensor itself (Young et al., 2017). Operations that are performed before the main evaluation of the data are considered pre-processing (Campbell, Wynne, 2011). The majority of pre-processing operations fall into the categories of geometric, absolute, and relative preprocessing (Young et al., 2017). Geometric pre-processing is performed to achieve accurate image location and includes image orthorectification and georeferencing (Young et al., 2017). Adjustments for effects of the sun, topography, the atmosphere, and the sensor are included in absolute preprocessing, with absolute pre-processing aiding in values being able to be evaluated with other values of the same amount of pre-processing that were acquired from different sensors, times, or locations (Young et al., 2017). Relative pre-processing is performed to bring about radiometric scale equivalence between matching bands of a reference image and an evaluated image (Young et al., 2017).

\subsection{Data Types}

Light that is reflected from features on the Earth's surface is registered by a satellite scanner as brightness, or radiance (Campbell and Wynne, 2011, Young et al., 2017), in $\mathrm{W}$ • micrometer $^{-1} \cdot \operatorname{steradian}^{-1} \cdot \mathrm{m}^{-2}$ (Campbell and Wynne, 2011). The analog signals from the sensor are turned into numbers (Ose et al., 2016). A pixel in a digital image stores the brightness data as numeric values that are called digital numbers (DNs) (Campbell and Wynne, 2011). Digital numbers are noted as binary bits that function as a scale denoting approximate brightness (Campbell and Wynne, 2011). The number of bits determines how many values can be registered for each sensor band and the overall image (Campbell and Wynne, 2011). Data across the Landsat sensors vary in bits, with data from MSS being 6- and 7-bit, TM and ETM+ being 8-bit, and OLI being 12-bit (USGS, 2019b).

Since digital numbers do not give radiance in physical units (Campbell and Wynne, 2011), digital numbers cannot be used to evaluate spectral values through time (Young et al., 2017), and digital numbers cannot be used to evaluate brightness in physical units from one scene to another (Campbell and Wynne, 2011). However, the metadata files of satellite images contain calibration coefficients that can be utilized to obtain absolute radiance from digital numbers; this radiance is commonly called at-sensor radiance and is one of the ways that an image can be pre-processed (Young et al., 2017). 
Additional absolute pre-processing can be performed beyond atsensor radiance (Young et al., 2017). The sun's angle of elevation, length between the Sun and the Earth, and exoatmospheric irradiance from the sun can be addressed by calculating top-of-the-atmosphere reflectance (TA), which gives the amount of reflected radiation that is being received by a sensor at the top of the atmosphere (Young et al., 2017).

Converting TA data to surface reflectance aims to minimize how electromagnetic radiation is impacted by particles such as atmospheric aerosols, water vapor, and gases (Young et al., 2017). The radiative transfer models used in calculating surface reflectance for Landsat 4-5, and 7 is the $6 \mathrm{~S}$ method (Vermote et al., 1997, USGS, 2019a), whereas Landsat 8 uses an internal algorithm (USGS, 2019a).

\subsection{Landsat Data Product Structure and Processing}

Data products from images procured from Landsat missions 1-8 are available in Landsat Collection 1 (USGS, 2018). Within Landsat Collection 1, there are three tiers (USGS, 2018). Depending on the amount of processing performed and quality, data products are designated as Real-Time (RT), Tier 1 (T1), or Tier 2 (T2) (USGS, 2018). After receiving preliminary processing, data from Landsat $8 \mathrm{OLI} / \mathrm{TIRS}$ and Landsat 7 $\mathrm{ETM}+$ are placed into the Real-Time tier; this data is subsequently processed again and moved into Tier 1 or Tier 2 (USGS, 2018). Products in Tier 1 fulfill specific quality requirements; Tier 2 products are lower in quality compared to products in Tier 1 (USGS, 2018).

During Level 1 Processing, MSS data are scaled from 6- and 7bit data to 8-bit, and OLI data are scaled from 12-bit to 16-bit (USGS, 2019b). Additional processing information can be found in the Landsat Collection 1 Level 1 Product Definition (USGS, 2019b).

The possibility that pre-processing could cause artifacts or errors has been noted (Campbell and Wynne, 2011, Young et al., 2017). Roy et al. (2016) has also evaluated Normalized Difference Vegetation Index (NDVI) values between Landsat 7 $\mathrm{ETM}+$ and Landsat 8 OLI for both surface reflectance and top of the atmosphere. However, there is a lack of studies evaluating the effects of the conversion of digital numbers to top-of-the-atmosphere and surface reflectance values on spectral indices.

Given the wide variety of practical applications for which Landsat images are used, understanding if there are effects in derived products from the underlying image pre-processing is needed. This study evaluated the conversion of digital numbers to top-of-the-atmosphere and surface reflectance values on select spectral indices calculated for five cover classes.

\section{MATERIALS AND METHODS}

\subsection{Image Acquisition and Pre-processing}

Four Landsat 5 Thematic Mapper (TM) and two Landsat 8 Operational Land Imager (OLI) scenes were downloaded from Landsat Collection 1 from USGS Earth Explorer. Scenes were acquired in 1998, 2000, 2002, 2004, 2014, and 2016. Each of the six scenes was downloaded as compressed files in three preprocessing levels: digital number (DN), top-of-the-atmosphere (TA), and surface reflectance (SR) for a total of eighteen scenes.
From each compressed file, the three visible and three infrared bands were extracted and stacked for a total of six bands.

\subsection{Study Site Description}

Spectral reflectance and DN values were extracted from these images for the following classes: predominately mixed conifers (MC), predominately Northern Mixed Grass Prairie (NMGP), deep water (DW), shallow water (SW), and edge water (EW).

2.2.1 Predominately Mixed Conifers: The MC cover class pixels were extracted from an area on National Forest land within the Black Hills of South Dakota (SD). The main tree species in the Black Hills is the ponderosa pine (Pinus ponderosa), but also includes other tree species such as Rocky Mountain juniper (Juniperus scopulorum), quaking aspen (Populus tremuloides), white spruce (Picea glauca), and bur oak (Quercus macrocarpa) (Walters et al., 2013). Mean annual precipitation in the nearby town of Custer, SD is 49.91 centimeters $(\mathrm{cm})$ and mean annual temperature is $6.83^{\circ} \mathrm{C}$ $\left(44.3^{\circ} \mathrm{F}\right.$ ) (Arguez et al., 2010).

An area to the southwest of Jewel Cave National Monument [43.729832, -103.829320] was selected for its relative homogeneity in canopy cover and size. These sites were initially identified with Google Maps and later confirmed through field visits. From visual inspection, the stands appeared to be dominated by ponderosa pine with interspersed Rocky Mountain juniper. Due to the mixture of conifer species and potential for understory vegetation to also be a part of the spectral reflectance, the cover class was designated as predominately MC.

Additionally, the closest year available in Google Earth Pro was used to evaluate historic ground conditions and to ensure uniformity in canopy cover and tree condition (live or dead) across time for each sampling location. Google Earth Pro was also used to establish approximate $90 \times 90$-meter $(\mathrm{m})$ plots for each image of the closest year to the corresponding Landsat image. Geographic coordinates were recorded from each plot in ERDAS Imagine using a combination of Google Earth Pro and Google Maps.

2.2.2 Predominately Northern Mixed Grass Prairie: For the predominately NMGP class, an area of land in northeastern Wyoming (WY) was chosen approximately five miles north of the town of Newcastle, WY [43.854969, -104.206915]. This area was selected due to its familiarity, and site location was determined by viewing Google Maps for size and relative homogeneity in cover. While ground inspection of the site was not performed, major species in the northern mixed grass prairie of the United States are needle-and-thread (Hesperostipa comata), western wheatgrass (Pascopyrum smithii), and blue grama (Bouteloua gracilis) (Singh et al., 1983).

The closest year available in Google Earth Pro was also used for the NMGP cover class to evaluate historic ground conditions and try to ensure the most uniformity in grass ground cover for each sampling location. The cover class was designated as predominately mixed NMGP to account for additional variables, such as bare ground or rock. Google Earth Pro was again used to establish approximate $90 \times 90$-meter $(\mathrm{m})$ plots for each image of the closest year to the corresponding Landsat image. Geographic coordinates were recorded from each plot in ERDAS Imagine using a combination of Google Earth Pro and Google Maps. 
2.3 Water Cover Classes: For the three water classes, Keyhole Reservoir [44.360154, -104.850673] in northeastern Wyoming was selected. A bathymetric map of Keyhole (Ferrari, 2005) was used for ocular selection of areas that were shallow and deep water, with shallow water being designated as approximately $1240 \mathrm{~m}$ (4070 feet) to $1245 \mathrm{~m}$ (4085 feet) in elevation on the map. Deep water was considered to fall between approximately $1228 \mathrm{~m}$ (4030 feet) to $1231 \mathrm{~m}$ (4040 feet) in elevation on the map. Pixels that appeared along the perimeter of the waterbody and possessed mixed coloring between the waterbody and the land were visually selected as edge water. Geographic coordinates were recorded from ERDAS Imagine for each sample.

\subsection{Data collection}

File pixel values were extracted using the 'Inquire' function in ERDAS Imagine for the five cover classes. For every year, the three pre-processed images (DN, TA, SR) were displayed in the ERDAS viewer and file pixel values were collected from the same latitude and longitude for each pre-processed image. The number of samples per cover class varied, with numbers ranging from seven to fourteen depending on site suitability. Additional samples were limited for certain years due to variables including cloud cover, differences in vegetation cover, canopy closure, or tree health.

\subsection{Spectral Indices}

Spectral indices were calculated from the file pixel values for each product level across time. Select water and vegetation indices are given in Table 1.

\begin{tabular}{|c|c|c|c|}
\hline $\begin{array}{l}\text { Cover } \\
\text { Class }\end{array}$ & Index & Formula & Reference \\
\hline $\begin{array}{l}\text { MC } \\
\text { NMGP } \\
\text { EW }\end{array}$ & NDVI & $\begin{array}{l}\text { NIR-Red/ } \\
\text { NIR+Red }\end{array}$ & Rouse et al., 1973 \\
\hline $\begin{array}{l}\text { MC } \\
\text { NMGP } \\
\text { EW }\end{array}$ & $\begin{array}{l}\text { Simple } \\
\text { Ratio }\end{array}$ & $\begin{array}{l}\text { Red/ } \\
\text { NIR }\end{array}$ & $\begin{array}{l}\text { Pearson and Miller, } \\
1972 \dagger\end{array}$ \\
\hline $\begin{array}{l}\text { MC } \\
\text { NMGP } \\
\text { EW }\end{array}$ & $\begin{array}{l}\text { Vegetation } \\
\text { Index }\end{array}$ & $\mathrm{NIR} / \mathrm{R}$ & $\begin{array}{l}\text { Lillesand and Kiefer, } \\
1987 \dagger \\
\text { Jordan, } 1969\end{array}$ \\
\hline $\begin{array}{l}\text { DW } \\
\text { SW } \\
\text { EW }\end{array}$ & NDWI & $\begin{array}{l}\text { Green-NIR/ } \\
\text { Green+NIR }\end{array}$ & McFeeters, 1996 \\
\hline $\begin{array}{l}\text { DW } \\
\text { SW } \\
\text { EW }\end{array}$ & MNDWI & $\begin{array}{l}\text { Green- } \\
\text { SWIR/ } \\
\text { Green+SWIR }\end{array}$ & $\mathrm{Xu}, 2006$ \\
\hline $\begin{array}{l}\text { DW } \\
\text { SW } \\
\text { EW }\end{array}$ & WII* & $\begin{array}{l}\mathrm{NIR}^{\wedge} 2 / \\
\text { Red }\end{array}$ & Caillaud et al., $1991 \dagger$ \\
\hline $\begin{array}{l}\text { DW } \\
\text { SW } \\
\text { EW }\end{array}$ & MWII** & $\begin{array}{l}\operatorname{SWIR}^{\wedge} 2 / \\
\text { Red }\end{array}$ & Davrache et al., 2013 \\
\hline $\begin{array}{l}\text { DW } \\
\text { SW } \\
\text { EW }\end{array}$ & $\mathrm{WI} * * *$ & $\begin{array}{l}\text { NIR^2/ } \\
\text { Green }\end{array}$ & Davrache et al., 2013 \\
\hline $\begin{array}{l}\text { DW } \\
\text { SW } \\
\text { EW }\end{array}$ & MWI**** & $\begin{array}{l}\mathrm{SWIR}^{\wedge} 2 / \\
\text { Green }\end{array}$ & Davrache et al., 2013 \\
\hline
\end{tabular}

Table 1. Spectral indices calculated for a given cover class. NOTES: *Water Impoundment Index; **Modified Water Impoundment Index; ***Water Index; ****Modified Water Index; $\uparrow$ As cited in Davranche et al., 2013
Both vegetation and water indices were calculated for the edge water pixels due to the potential for vegetation to be incorporated in the pixel. Formula for these indices were adjusted to accommodate the coastal blue and cirrus bands of OLI.

Paired, two-tailed t-tests were calculated between the different product levels for each index to determine the significance between index averages. Since this experiment was evaluating recurrent measurements from the same groups (MC, NMGP, DW, SW, and EW), standard error bars are not applicable for determining significance (Cumming et al., 2007). Hence difference in averages were compared at an alpha value of 0.05 .

\section{RESULTS}

\subsection{Vegetation}

All three vegetation indices computed for both vegetation cover classes (predominately mixed conifer and predominately Northern Mixed Grass Prairie) exhibited a significant difference $(p<0.001)$ between each pre-processing level for all six years.

3.1.1 Predominately Mixed Conifers: Index values from all three pre-processing levels calculated from reflectance of MC pixels were consistently different from each other. There was a significant difference $(\mathrm{p}<0.001)$ between each pre-processing level for the three indices calculated across all six years (Fig. 1).

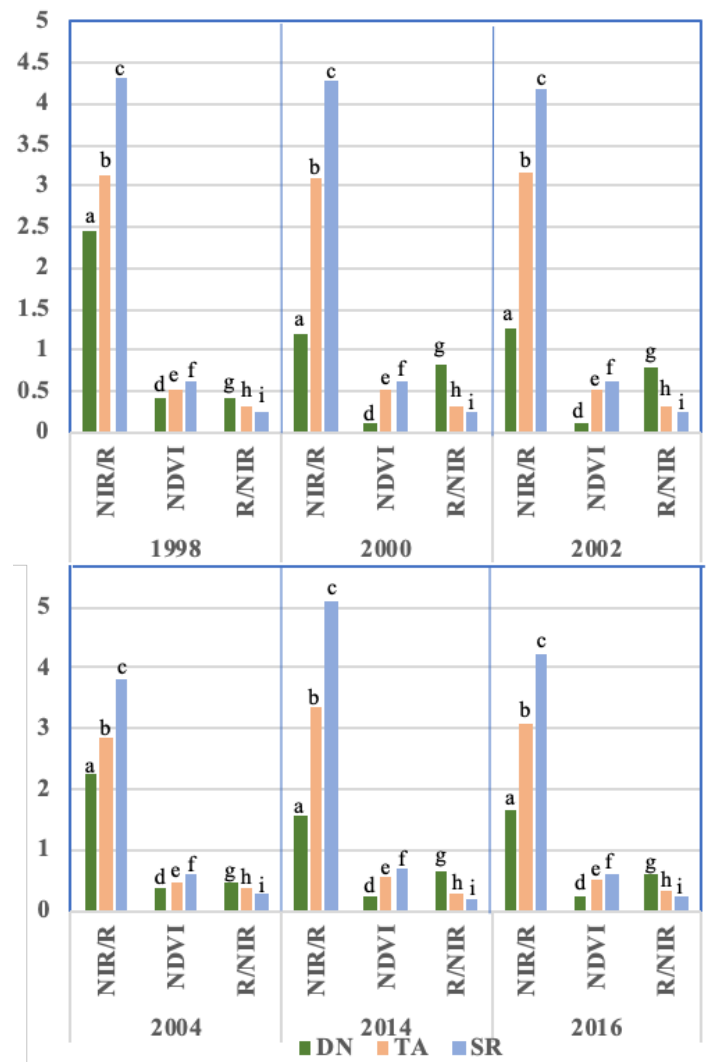

Figure 1. Average values of the Vegetation Index (NIR/R), Normalized Difference Vegetation Index (NDVI), and Simple Ratio Index (R/NIR) for predominately mixed conifer at three pre-processing levels (DN, TA, SR) across six years. Letters denote significant difference $(\mathrm{p}<0.001)$ between pre-processing levels within a given index. Average index values for preprocessing levels were not compared across different indices. 
3.1.2 Predominately Northern Mixed Grass Prairie: Index values calculated from reflectance of NMGP pixels were also consistently different between data products, with there being a significant difference $(\mathrm{p}<0.001)$ between each pre-processing level for the three indices calculated across all six years (Fig. 2).
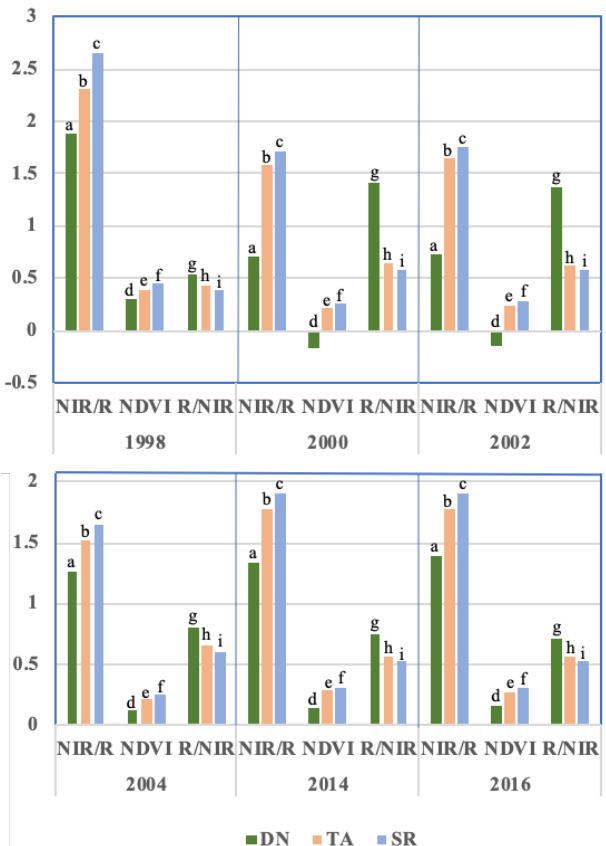

Figure 2. Average values of the Vegetation Index (NIR/R), Normalized Difference Vegetation Index (NDVI), and Simple Ratio Index (R/NIR) for predominately Northern Mixed Grass Prairie at three pre-processing levels (DN, TA, SR) across six years. Letters denote significant difference $(p<0.001)$ between pre-processing levels within a given index. Average index values for pre-processing levels were not compared across different indices.

\subsection{Water}

Average index values exhibited less consistency in significant difference between the three levels of pre-processing. Deep water exhibited the highest consistency of significant difference ( $<<0.05$ for $106 / 108 p$-values), with shallow water exhibiting lower consistency $(\mathrm{p}<0.05$ for $101 / 108 \mathrm{p}$-values $)$, and edge water pixels exhibiting the least amount of consistency in significant difference between the three levels of pre-processing ( $<<0.05$ for $133 / 162 p$-values). The edge water had a greater number of $\mathrm{p}$-values calculated in comparison to deep water or edge water due to the three vegetation indices that were also computed for edge water.

3.2.1 Deep Water: There was a significant difference ( $p$ $<0.05$ ) between each pre-processing level for the three indices calculated across all six years for DW pixels with only two exceptions (Fig. 3, Fig. 4). For the NDWI index calculated from a scene collected on July $6^{\text {th }}, 1998$ scene, there was not a significant difference between values calculated from digital number and surface reflectance products $(\mathrm{p}=0.71)$ (Fig. 3).

The MNDWI index calculated for a scene collected on June $23^{\text {rd }}, 2002$ also exhibited a non-significant difference between values calculated from digital number and surface reflectance products $(\mathrm{p}=0.10)($ Fig. 3).

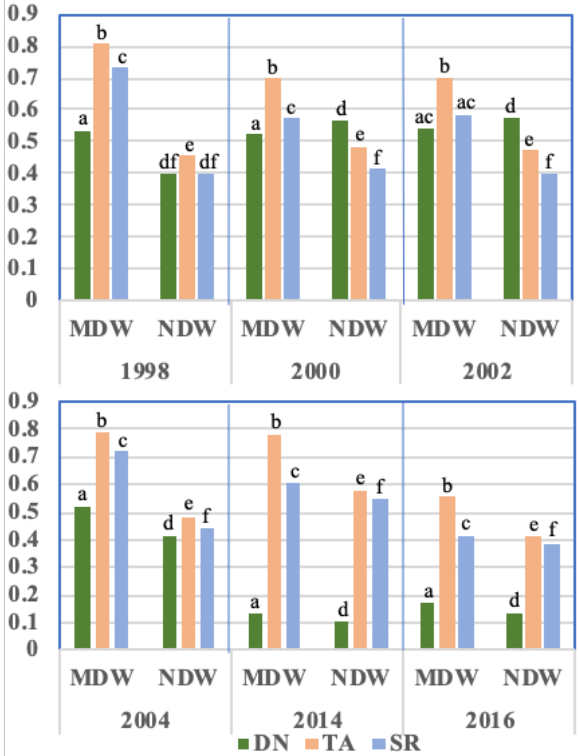

Figure 3. Average values of the Modified Normalized Difference Water Index (abbreviated MDW in the graph) and the Normalized Difference Water Index (abbreviated NDW in the graph) of deep water for three pre-processing levels (DN, TA, SR) across six years. Letters denote significant difference $(p<0.05)$ between pre-processing levels within a given index.

Average index values for pre-processing levels were not compared across different indices.

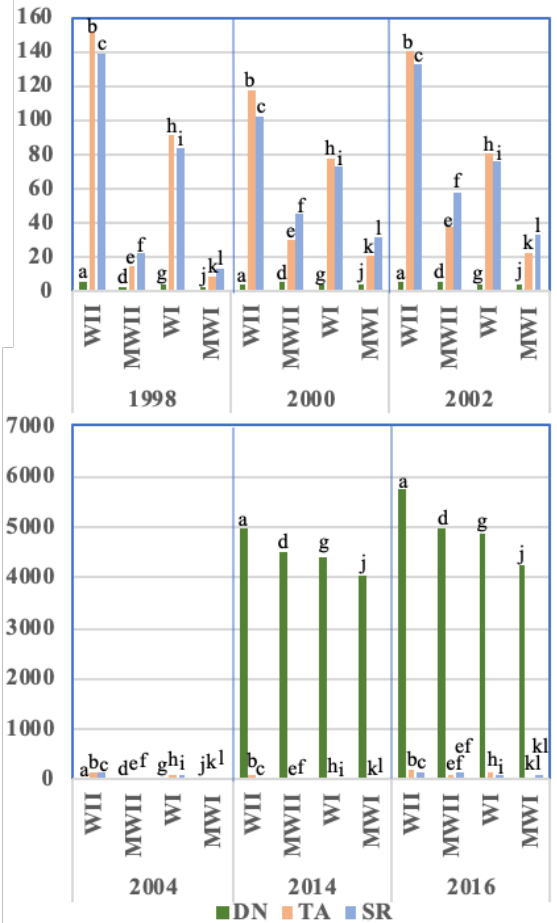

Figure 4. Average values of the Water Impoundment Index (WII), Modified Water Impoundment Index (MWII), Water Index (WI), and Modified Water Index (MWI) of deep water for three pre-processing levels (DN, TA, SR) across six years. Letters denote significant difference $(\mathrm{p}<0.05)$ between preprocessing levels within a given index. Average index values for pre-processing levels were not compared across different indices. 
3.2.2 Shallow Water: Index values calculated from reflectance of SW pixels exhibited less consistency in significant difference across data products in comparison to DW and vegetation cover classes. The majority $(101 / 108)$ of $\mathrm{p}$ values between data products across the six years were significant $(\mathrm{p}<0.05)($ Fig. 5, 6). Four years had one insignificant $\mathrm{p}$-value and one year had three insignificant p-values (Table 2, Fig. 5, 6). In the year 2000, all p-values were significant (Fig. 5, 6). Four of the seven insignificant p-values were calculated from the NDWI index, with one p-value being from the DN-SR comparison, and the other three values resulting from the TASR comparison (Table 2, Fig. 5).

\begin{tabular}{|c|c|c|c|c|}
\hline \multirow{2}{*}{ Year } & \multirow{2}{*}{ Index } & \multicolumn{3}{|c|}{ Pre-processing Levels Compared } \\
& & DN-TA & \multicolumn{1}{c|}{ DN-SR } & \multicolumn{1}{c|}{ TA-SR } \\
\hline $7 / 6 / 98$ & $N D W I$ & $1.43 \mathrm{E}-09$ & $\mathbf{1 . 5 0 E}-01$ & $3.00 \mathrm{E}-02$ \\
$6 / 23 / 02$ & $N D W I$ & $3.31 \mathrm{E}-07$ & $1.20 \mathrm{E}-05$ & $\mathbf{9 . 0 3 E - 0 2}$ \\
$8 / 7 / 04$ & $N D W I$ & $4.76 \mathrm{E}-11$ & $1.26 \mathrm{E}-06$ & $\mathbf{2 . 8 1 E - 0 1}$ \\
$9 / 20 / 14$ & $N D W I$ & $1.37 \mathrm{E}-11$ & $2.54 \mathrm{E}-08$ & $\mathbf{7 . 2 9 E - 0 1}$ \\
$6 / 21 / 16$ & $M N D W I$ & $6.79 \mathrm{E}-10$ & $5.89 \mathrm{E}-08$ & $\mathbf{9 . 7 9 E - 0 2}$ \\
$6 / 21 / 16$ & $M W I I$ & $2.29 \mathrm{E}-09$ & $2.07 \mathrm{E}-09$ & $\mathbf{1 . 8 5 E - 0 1}$ \\
$6 / 21 / 16$ & $M W I$ & $2.79 \mathrm{E}-09$ & $2.60 \mathrm{E}-09$ & $\mathbf{1 . 1 8 E - 0 1}$ \\
\hline
\end{tabular}

Table 2. P-values from years that exhibited an insignificant difference $(p>0.05)$ between select indices calculated from DN,

$\mathrm{TA}$, and SR pre-processing levels for shallow water. Bold numbers denote insignificant $\mathrm{p}$-values.

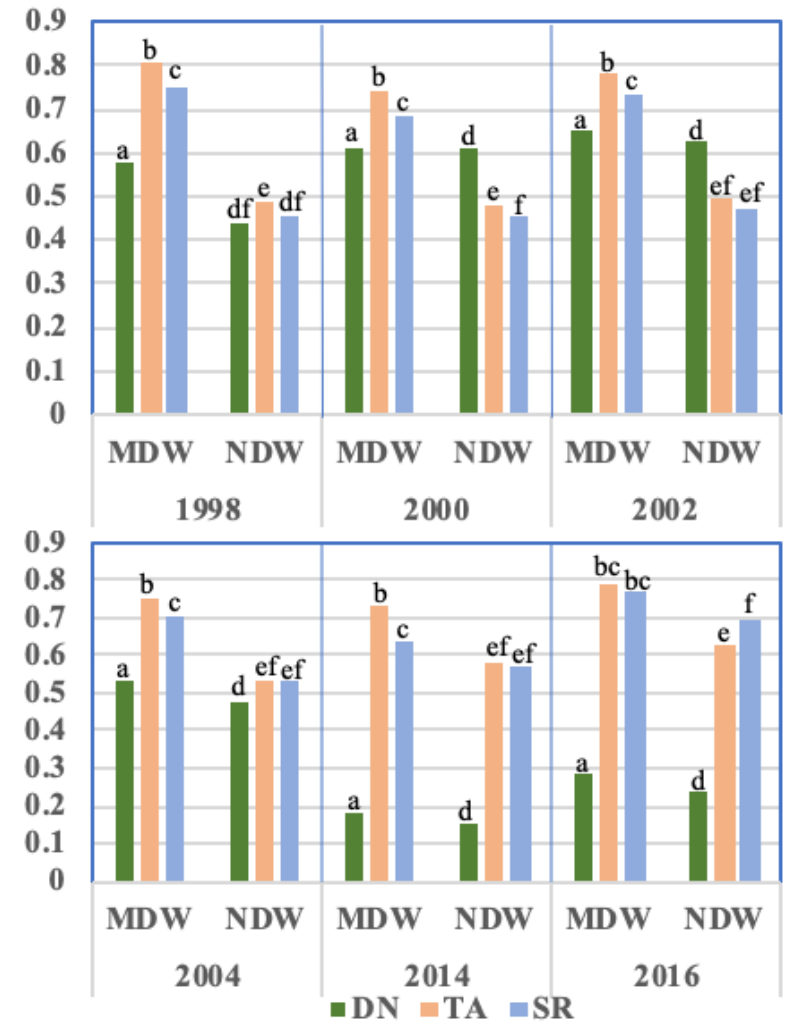

Figure 5. Average values of the Modified Normalized Difference Water Index (abbreviated MDW in the graph) and the Normalized Difference Water Index (abbreviated NDW in the graph) of shallow water for three pre-processing levels (DN, TA, SR) across six years. Letters denote significant difference $(p<0.05)$ between pre-processing levels within a given index.
Average index values for pre-processing levels were not compared across different indices.

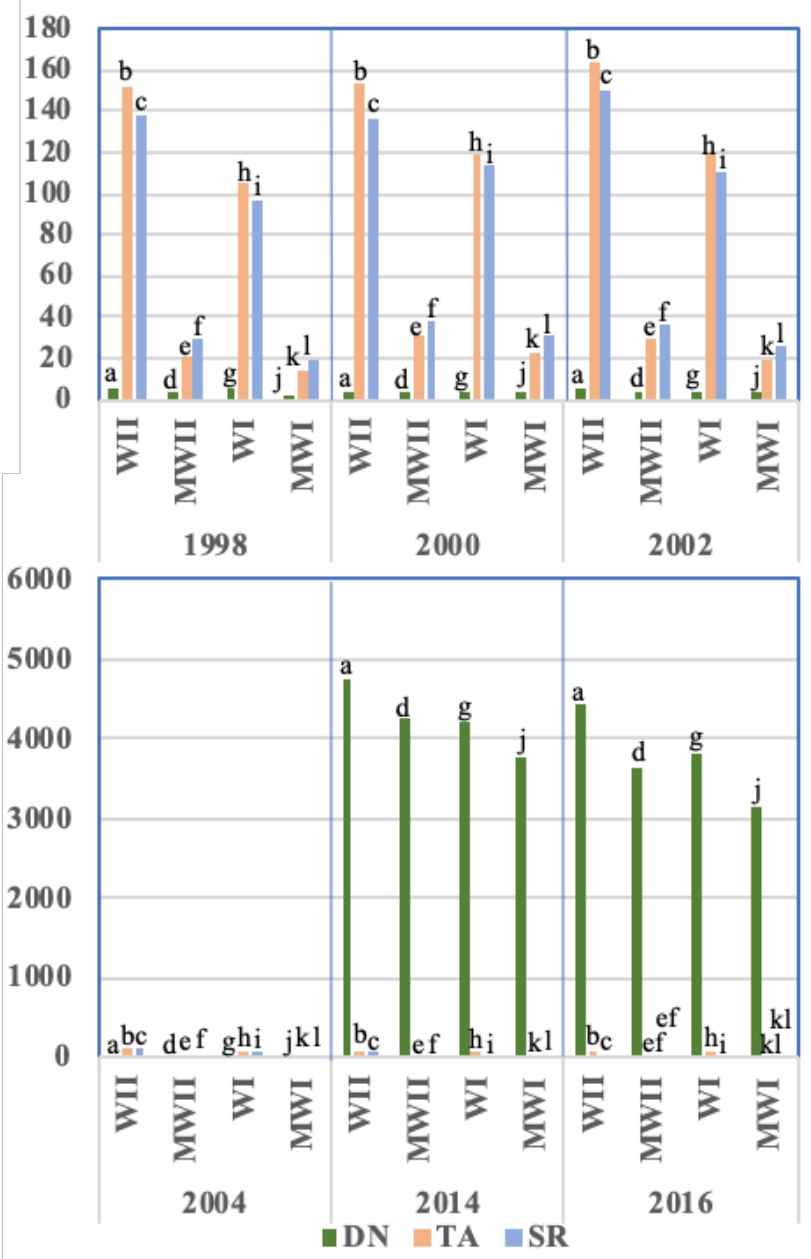

Figure 6. Average values of the Water Impoundment Index (WII), Modified Water Impoundment Index (MWII), Water Index (WI), and Modified Water Index (MWI) of shallow water for three pre-processing levels (DN, TA, SR) across six years. Letters denote significant difference $(\mathrm{p}<0.05)$ between preprocessing levels within a given index. Average index values for pre-processing levels were not compared across different indices.

3.2.3 Edge Water: The EW pixels exhibited the most inconsistency in significant difference between the three levels of pre-processing. The majority of average index values exhibited a significant difference $(p<0.05)$ between the three levels of pre-processing (Fig. 7, 8, 9). However, out of 162 average index values calculated, there were 29 instances where there was not a significant difference $(p>0.05)$ between levels of pre-processing (Table 3).

The majority (27/29) of insignificant values between the three levels of pre-processing came from the indices calculated from scenes acquired by Landsat 8 OLI in years 2014 and 2016 (13 and 14 insignificant values, respectively) (Table 3, Fig. 7, 8, 9). The NDWI had the most insignificant values (4/29) out of all the indices (Table 4, Fig. 8). 


\begin{tabular}{|c|c|c|c|c|}
\hline \multirow{2}{*}{ Year } & \multirow[t]{2}{*}{ Index } & \multicolumn{3}{|c|}{$\begin{array}{l}\text { Pre-processing Levels } \\
\text { Compared }\end{array}$} \\
\hline & & N-TA & DN-SR & TA-SR \\
\hline $7 / 6 / 5$ & 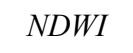 & $30.010-01$ & 06 & 4.05E-06 \\
\hline $8 / 7 /($ & 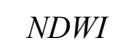 & 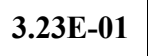 & 05 & $.68 \mathrm{E}-07$ \\
\hline $9 / 20 / 14$ & $N I R / R$ & $5.06 \mathrm{E}-01$ & 2.33E-01 & $3.07 \mathrm{E}-02$ \\
\hline $9 / 20 / 14$ & $N D i$ & $6.71 \mathrm{E}-01$ & 8.39E-01 & $7.09 \mathrm{E}-03$ \\
\hline $9 / 20 / 14$ & $M N D W I$ & 2.00E-01 & 7.24E-01 & $9.20 \mathrm{E}-07$ \\
\hline $9 / 20 / 14$ & $N D W I$ & $2.59 \mathrm{E}-01$ & $9.33 E-01$ & 7.97E-04 \\
\hline $9 / 20 /$ & $I$ & 7.95E-07 & 2.0 & $67 \mathrm{E}-01$ \\
\hline $9 / 20 / 1$ & $W I$ & $1.94 \mathrm{E}-06$ & 3. & (1) \\
\hline $9 / 20 / 14$ & S & 年 & & 7.16E-02 \\
\hline $6 / 21 / 16$ & $N I R / R$ & $3.36 \mathrm{E}-01$ & 8.23E-01 & $9.47 \mathrm{E}-02$ \\
\hline $6 / 21 / 16$ & $N D V I$ & $7.47 \mathrm{E}-02$ & $2.05 \mathrm{E}-01$ & $5.50 \mathrm{E}-01$ \\
\hline $6 / 21 / 16$ & $M N D W I$ & $1.46 \mathrm{E}-02$ & 2.05E-01 & 2.24E-04 \\
\hline $6 / 21 / 16$ & $N D W I$ & $1.83 \mathrm{E}-02$ & 1.57E-01 & $7.21 \mathrm{E}-02$ \\
\hline $6 / 21 / 16$ & WII & $3.00 \mathrm{E}-05$ & $2.26 \mathrm{E}-05$ & $6.55 \mathrm{E}-01$ \\
\hline $6 / 21 / 16$ & $W I$ & $6.47 \mathrm{E}-05$ & $4.00 \mathrm{E}-05$ & $2.46 \mathrm{E}-01$ \\
\hline $6 / 21 / 16$ & $S k$ & $5.61 \mathrm{E}-02$ & $1.20 \mathrm{E}-01$ & 3.94E-01 \\
\hline
\end{tabular}

Table 3. P-values from years that exhibited an insignificant difference $(\mathrm{p}>0.05)$ between select indices calculated from $\mathrm{DN}$,

TA, and SR pre-processing levels. Bold numbers denote insignificant $\mathrm{p}$-values.
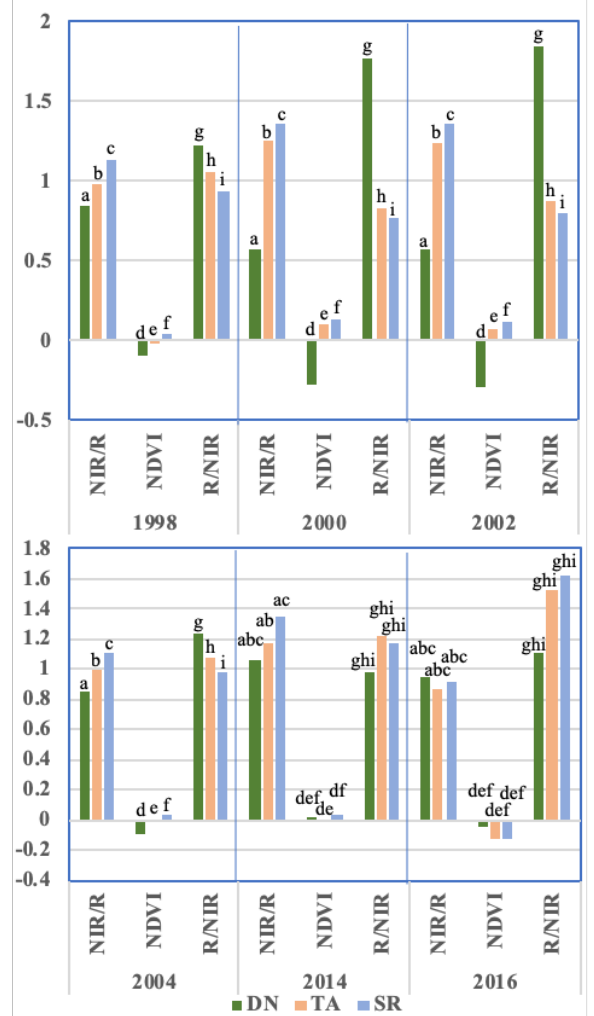

Figure 7. Average values of the Vegetation Index (NIR/R), Normalized Difference Vegetation Index (NDVI), and Simple

Ratio Index (R/NIR) of the edge water class for three preprocessing levels (DN, TA, SR) across six years. Letters denote significant difference $(\mathrm{p}<0.05)$ between pre-processing levels within a given index. Average index values for pre-processing levels were not compared across different indices.

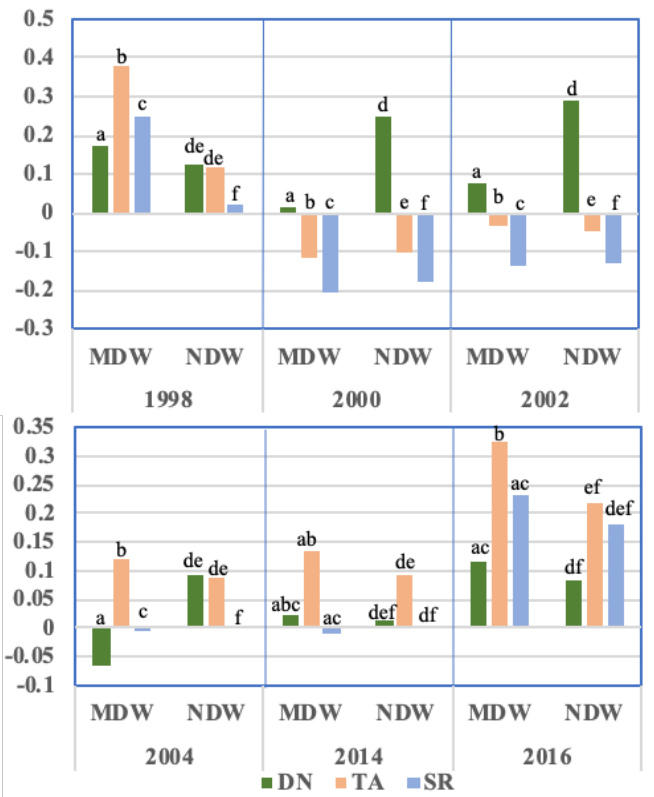

Figure 8. Modified Normalized Difference Water Index (MDW) and Normalized Difference Water Index (NDW) of the edge water class for three pre-processing levels (DN, TA, SR) across six years. Letters denote significant difference $(p<0.05)$ between pre-processing levels within a given index. Average index values for pre-processing levels were not compared across different indices.

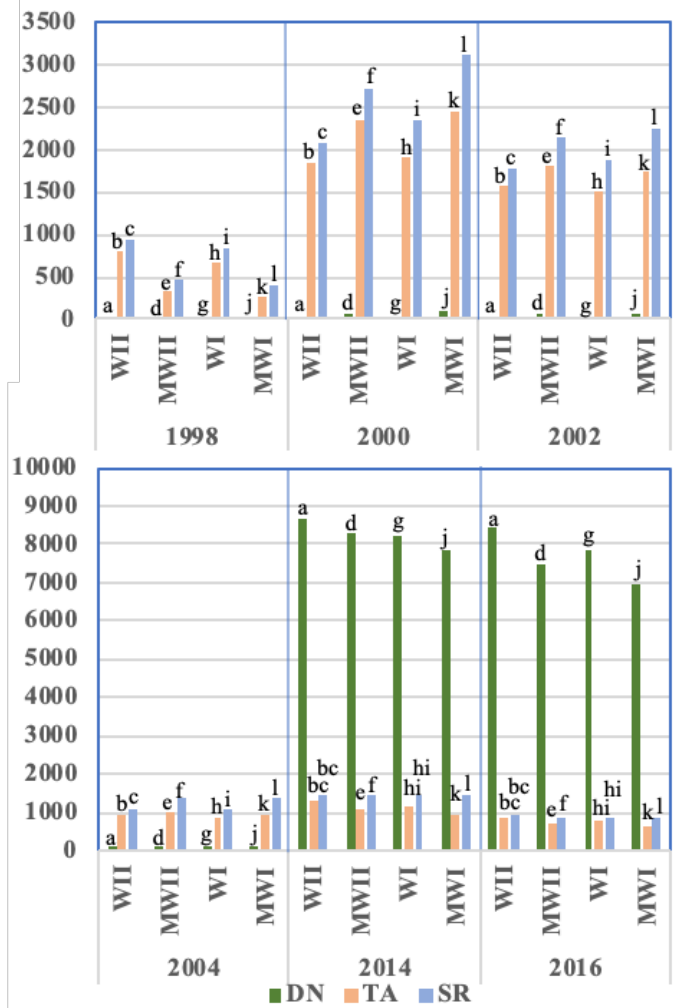

Figure 9. Average values of the Water Impoundment Index (WII), Modified Water Impoundment Index (MWII), Water Index (WI), and Modified Water Index (MWI) of edge water for three pre-processing levels (DN, TA, SR) across six years. 
Letters denote significant difference $(\mathrm{p}<0.05)$ between preprocessing levels within a given index. Average index values for pre-processing levels were not compared across different indices.

\section{DISCUSSION AND CONCLUSIONS}

\subsection{Vegetation}

There was a significant difference in average index values across year, sensor (Landsat $5 \mathrm{TM}$, Landsat $8 \mathrm{OLI}$ ), index, vegetation cover class (MC, NMGP), and pre-processing level (DN, TA, SR). Users need to be aware that different levels of pre-processing in vegetation could have higher or lower average index values due to pre-processing effects rather than due to vegetation characteristics and conditions. All average index values exhibited consistent, highly significant differences $(p<0.001)$ between different levels of pre-processing. Therefore, individuals who are employing indices to create maps need to be careful when comparing products generated from different levels of pre-processing in order to make accurate conclusions about ground conditions. Further research into the effects of pre-processing on spectral indices using additional vegetation cover classes, more indices, and a larger sample size is needed.

\subsection{Water}

Overall, average index values from different levels of preprocessing for Landsat satellites 5 and 8 for all three water cover classes (DW, SW, EW) were not consistently affected by pre-processing. Significant difference in average index values varied by year, by sensor, by index, by water feature, and by pre-processing level (DN, TA, SR).

Pre-processing did not systematically affect average index values across all years. For some images, all average index values were significantly different whereas other images from other years had multiple average index values that were not significant from one another. Even across images from different years that were collected by the same sensor, significance between average index values of the three levels of preprocessing was not always consistent.

Moreover, data acquired by both sensors were not affected by pre-processing equally. Landsat 8 OLI data had less significant differences than did Landsat $5 \mathrm{TM}$ data for both EW and SW. However, Landsat 5 data had fewer significant values for DW than Landsat 8 data. Average index values of edge water from Landsat 8 data had fewer significant differences between levels of pre-processing in comparison to index values of edge water from Landsat 5 data, or deep and shallow water from Landsat 8 or Landsat 5 data. Furthermore, the average index values of the WII, MWII, WI, and MWI calculated from the DN level of preprocessing were very high in comparison to the average index values calculated from TA and SR for scenes acquired by Landsat 8 in 2014 and 2016. This large difference in values from Landsat 8 may not only be due to the differences in preprocessing levels and requires further investigation.

Additionally, some index values were not consistently significantly different across all years. However, out of the six water indices that were calculated, MNDWI and NDWI had at least one insignificant difference between index values of the varying pre-processing levels for each water cover class. This lack of predictability in whether or not MNDWI or NDWI values significantly differ between pre-processing levels is important for users to be informed of as MNDWI and NDWI are widely used. Additional research should evaluate why specific bands that have been pre-processed to a certain level are resulting in average index values being significantly different from one another.

Pre-processing effects also appeared to decrease along a gradient that occurred with the lake's physical characteristics. Deep water was the most impacted by pre-processing and edge water was the least impacted by pre-processing effects. Shallow water was intermediately affected.

Furthermore, there was not a pre-processing level that consistently exhibited the highest or lowest average index value across all indices nor within an index for all years. Significant differences in the average index values between the preprocessing levels (DN-TA, DN-SR, TA-SR) was also not consistent across all years or indices. Further research to evaluate why a significant difference exists between average index values from DN-SR, but not between DN-TA or TA-SR is needed.

The lack of consistency in the significance between levels of pre-processing and the lack of consistency in size of average index values across the three pre-processing levels demonstrates the need for further research to be performed into the effects of pre-processing on spectral indices used with water. A larger sample size, additional water indices, and use of further satellites should be investigated.

Users of Landsat satellite data need to be aware of the effects of pre-processing on spectral indices calculated from water classes are not predictable. This lack of predictability also demonstrates the importance of specifying what level of pre-processing was used to generate derived products, such as maps, in addition to specifying what indices are being used. Additionally, users should be aware of what pre-processing level was used in the creation of threshold values for image classification. Due to the differences in index values within the same index for different levels of pre-processing, index values could be falling above or below the threshold as a result of pre-processing rather than actual ground conditions. Caution should be exhibited when trying to compare derived products that are generated using different indices or different pre-processing levels due to the current lack of predictability in the effects that pre-processing has across satellites and indices on waterbodies.

In conclusion, levels of pre-processing have varied effects on spectral index values calculated for vegetation and water features. Users need to exercise caution in selecting a level of pre-processing for their data or when comparing data products derived from different levels of pre-processing.

\section{ACKNOWLEDGEMENTS}

We would like to thank WyomingView for project support. Thank you to the United States Geological Survey for providing no-cost Landsat data and AmericaView. Thank you to Kay Gettinger for her support during this project and review assistance. The authors declare no conflict of interest.

This material is based upon work supported by the U.S. Geological Survey under Grant/Cooperative Agreement No. G18AP00077 to the second author. The views and conclusions contained in this document are those of the authors and should not be interpreted as representing the opinions or policies of the U.S. Geological Survey. Mention of trade names or commercial 
products does not constitute their endorsement by the U.S. Geological Survey. This manuscript is submitted for publication with the understanding that the United States Government is authorized to reproduce and distribute reprints for Governmental purposes.

\section{REFERENCES}

Arguez, A., Durre, I., Applequist, S., Squires, M., Vose, R., Yin, X., Bilotta, R., 2010a. NOAA's U.S. Climate Normals (1981-2010). [Annual/Seasonal Normals, Custer, SD US]. NOAA National Centers for Environmental Information DOI: 10.7289/V5PN93JP [July 13 2020].

Arguez, A., Durre, I., Applequist, S., Squires, M., Vose, R., Yin, X., Bilotta, R., 2010b. NOAA's U.S. Climate Normals (1981-2010). [Annual/Seasonal Normals, Newcastle, WY US]. NOAA National Centers for Environmental Information DOI: 10.7289/V5PN93JP [13 July 2020].

Campbell, J.B., Wynne, R.H., 2011. Introduction to Remote Sensing, $5^{\text {th }}$ edition. The Guilford Press, NY.

Cumming, G., Fidler, F., Vaux, D.L., 2007. Error bars in experimental biology. Journal of Cell Biology 177(1), 7-11. DOI: $10.1083 /$ jcb.200611141.

Davranche, A., Poulin, B., Lefebvre, G., 2013. Mapping flooding regimes in Camargue wetlands using seasonal multispectral data. Remote Sensing of Environment 138, 165171. DOI: $10.1016 /$ j.rse.2013.07.015.

Ecker, M, 2020. Raising a glass in wine country to better water management. landsat.gsfc.nasa.gov/raising-a-glass-in-winecountry-to-better-water-management/ (7 July 2020).

Evangelista, P.H., Stohlgren, T.J., Morisette, J.T., Kumar, S., 2009. Mapping invasive Tamarisk (Tamarix): A comparison of single-scene and time-series analyses of remotely sensed data. Remote Sensing 1 (3), 519-533. DOI: 10.3390/rs1030519.

Ferrari, 2005. Keyhole Reservoir 2003 Sedimentation Survey: United States Department of the Interior Bureau of Reclamation, $21 \mathrm{p}$.

www.usbr.gov/tsc/techreferences/reservoir.html (12 July 2020).

Xu, H., 2006. Modification of normalised difference water index (NDWI) to enhance open water features in remotely sensed imagery. International Journal of Remote Sensing, 27(14), 3025-3033. DOI: 10.1080/01431160600589179.

Jiang, W., He, G., Long, T., Ni, Y. Liu, H., Peng, Y., Lv, K., Wang, G., 2018. Multilayer perceptron neural network for surface water extraction in Landsat 8 OLI satellite images. Remote Sensing. 10(5), 755. DOI: 10.3390/rs10050755.

Jordan, C.F., 1969. Derivation of leaf-area index from quality of light on the forest floor. Ecology 50(4), 663-666. DOI: $10.2307 / 1936256$.

McFeeters, S.K., 1996. The use of the Normalized Difference Water Index (NDWI) in the delineation of open water features. International Journal of Remote Sens. 17(7), 1425-1432. DOI: $10.1080 / 01431169608948714$.
Ose, K., Corpetti, T., Demagistri, L., 2016. Multispectral satellite image processing. In Baghdadi, N., Zribi, M. (Ed.), Optical Remote Sensing of Land Surface: Techniques and Methods, 57-124. DOI: 10.1016/B978-1-78548-102-4.50002-8.

Rouse, J.W., Haas, R.H., Schell, J.A., Deering, D.W., 1973. Monitoring vegetation systems in the Great Plains with ERTS. NASA Goddard Space Flight Center 3d ERTS-1 Symp., Vol. 1, Sect. A., 309-317. ntrs.nasa.gov/search.jsp?R=19740022614 (13 July 2020).

Roy, D.P., Kovalskyy, V., Zhang, H.K., Vermote, E.F., Yan, L., Kumar, S.S., Egorov, A. 2016. Characterization of Landsat-7 to Landsat- 8 reflective wavelength and normalized difference vegetation index continuity. Remote Sensing of Environment 185: 57-70. DOI: 10.1016/j.rse.2015.12.024.

Schroeder, T.A., Wulder, M.A., Healey, S.P., Moisen, G.G., 2011. Mapping wildfire and clearcut harvest disturbances in boreal forests with Landsat time series data. Remote Sensing of Environment, 115(6), 1421-1433. 10.1016/j.rse.2011.01.022.

Singh, J.S., Lauenroth, W.K., Heitschmidt, R.K., Dodd, J.L., 1983. Structural and functional attributes of the vegetation of northern mixed prairie of North America. Botanical Review 49(1), 117-149. DOI: 10.1007/BF02861010.

Sivanpillai, R., Jacobs, K.M., Mattilio, C.M., Piskorski, E.V., 2020. Rapid flood inundation mapping by differencing water indices from pre- and post-flood Landsat images. Frontiers of Earth Sciences DOI: 10.1007/s11707-020-0818-0.

Straub, C.L., Koontz, S.R., Loomis, J.B., 2019. Economic valuation of Landsat Imagery: USGS Open-File Report 20191112, 13 p. DOI: 10.3133/ofr20191112.

USGS, 2018. Landsat collections: USGS Fact Sheet 20183049, 2 p. DOI: $10.3133 /$ fs20183049.

USGS, 2019a. Landsat 8 surface reflectance code (LASRC) product guide, LSDS- 1368, Version 2.0. prd-wret.s3.us-west2.amazonaws.com/assets/palladium/production/atoms/files/LSD S-1368_L8_SurfaceReflectanceCode-LASRC_ProductGuidev2.pdf (16 July 2020).

USGS, 2019b. Landsat Collection 1 Level 1 product definition, LSDS-1656, Version 2.0. prd-wret.s3-us-west2.amazonaws.com/assets/palladium/production/atoms/files/LSD S-1656_\%20Landsat_Collection1_L1_Product_Definitionv2.pdf (17 July 2020).

Vermote, E.F., Tanre, D., Deuze, J.L., Herman, M., Morcette, J.-J., 1997. Second simulation of the satellite signal in the solar spectrum, 6S: an overview. Transactions on Geoscience and Remote Sensing, 35(3), 675-686. DOI: 10.1109/36.581987.

Walters, B.F., Woodall, C.W., Piva, R.J., Hatfield, M.A., Domke, G.M., Haugen, D.E, 2013. Forests of the Black Hills National Forest 2011. United States Department of Agriculture, United States Forest Service Resource Bulletin NRS-83. www.nrs.fs.fed.us/pubs/rb/rb_nrs83.pdf (12 July 2020).

Young, N.E. Anderson, R.S., Chignell, S.M., Vorster, A.G. Lawrence, R., Evangelista, P.H. 2017. A survival guide to Landsat preprocessing. Ecology 98(4), 920-932. DOI: 10.1002/ecy.1730. 